\title{
El potencial simbólico del trabajo estético del cuerpo
}

\section{Abilio Vergara Figueroa ${ }^{1}$ \\ Revisão técnica realizada por Natalia Cabanillas}

Resumen: El artículo desarrolla un análisis de los cambios históricos en las significaciones del cuerpo que se despliega desde, una carga simbólica que otorga estabilidad ontológica al ser y que depende del mito, el ritual y el control social comunitario, para devenir, en las últimas décadas - por la influencia de las grandes urbes y de la globalización -, en una materia susceptible de intervención que la moldee siguiendo las propuestas de un imaginario colectivo producido por los medios de comunicación, contribuyendo a su insignificancia. Sin embargo, en los últimos años se asiste a una nueva configuración imaginaria del cuerpo cuyas expresiones se vivencian en la presentación del cuerpo como imagenque-argumenta en los movimientos indígenas, juveniles, feministas, homosexuales, etc. que redescubren su potencial simbólico. Este potencial también se asoma en la violencia y el miedo.

Palabras clave: Cuerpo, Ciudad, Simbolismo, Imaginarios, Estética.

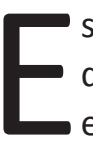

ste artículo tiene por finalidad proponer algunas consideraciones metodológicas para estudiar las relaciones entre los cuerpos y las ciudades en plural, amb@s-, además busca sugerir nuevas problemáticas surgidas para la habitación del cuerpo ${ }^{2}$ en el contexto de la globalización y en las nuevas condiciones de copresencia (el chat, por ejemplo) que posibilitan las nuevas tecnologías y la reformulación de biopolíticas que ya no provienen solamente de un centro (del poder, nacional, regional, institucional, mercantil), sino también desde múltiples agentes diseminados y con diverso poder que producen nuevas formas de sociabilidad, como también incertidumbre y miedo, como la irrupción de la violencia de diverso origen. Para una mejor comprensión de estas modificaciones, confrontaré las variables y categorías que surgen de dichas interrelaciones con las imágenes que aún pernean los imaginarios del cuerpo provenientes de la tradición comunitaria, que, como tendencia, sostenía al ser y su identidad, y sometía a la sanción colectiva la forma en que los sujetos usaban, presentaban y significaban sus cuerpos.

Esta propuesta se centra en las nuevas definiciones que se vienen ensayando, por un lado, en base al redescubrimiento de la potencia simbólica del trabajo estético sobre el cuerpo, considerando las nuevas posibilidades de su uso, exposición y concepción, especialmente en los nuevos movimientos sociales;
1. División de Estudios de Posgrado de la Escuela Nacional de Antropología e Historia, México. E-mail: abilio99@ hotmail.com

2. En cierta forma, el escenario en el que nos relacionamos con nuestro cuerpo se da por la escisión entre el yo y el cuerpo, puesto que entre ambos hay, como lo señala Margarita Baz, un "estado paradójico de vínculo obligado, posesión y extrañeza, sujeto a una dinámica incesante como expresión de la subjetividad", luego agrega que "la red de deseos que, jugados en el mundo, van haciendo historia, remiten a un cuerpo que ya no es el anatómico sino el cuerpo subjetivo, es decir, un cuerpo que habita un mundo simbólico, que se recrea en el plano imaginario y que se abisma en la dimensión de lo real" (idem: 29), (1999: 29). Esa "habitación" se puede vivir en el gozo, en la aceptación, el sufrimiento o la extrañeza y la repulsión, como también en la contemplación y la sobrevigilacia comunitaria o individual. 
y que, por otro lado, tienen su poderosa contraparte en la violencia que convierte en insignificante al cuerpo (por ejemplo, al usarlo como soporte material de mensajes del crimen organizado) y, de otro lado, en la promoción de esa misma insignificancia desde la moda y el consumismo.

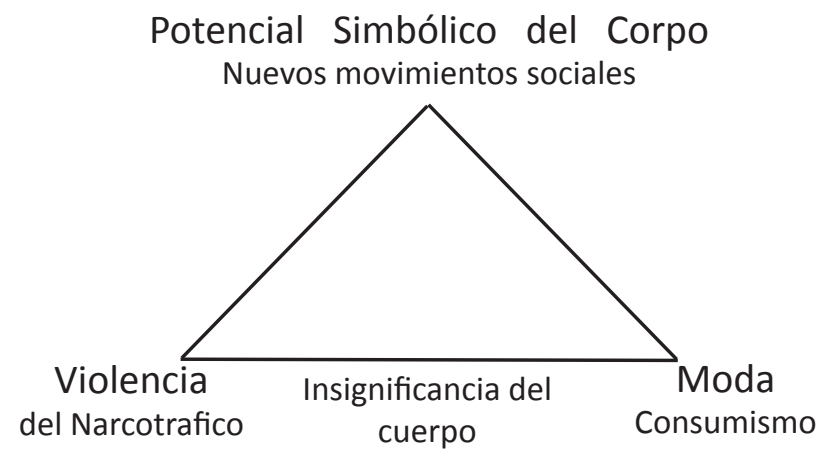

Éste es el triángulo donde el cuerpo se debate hoy. Éste es, a su vez, un dilema epocal. Al entenderlo como dilema, es necesario explorar las nuevas formas de reclusión que se vienen promoviendo desde diversas perspectivas económicosociales, culturales y de poder, que en algunos casos deriva en el declive de la significación social del cuerpo, aún cuando, a nivel individual, su vivencia se intensifique en dramas que son ocultadas por la indiferencia metropolitana (SIMMEL, 1988).

No obstante, para comprenderlo mejor, no debemos olvidar que el cuerpo contemporáneo es producto de una larga historia de transformaciones sociales y culturales que afectaron su imaginario: del cuerpo sagrado, que pierde tal condición por el pecado, pasa a ser cuerpo-templo, depositario de algo externo y eterno como es el alma, luego pasa a ser el cuerpo-máquina en la modernidad del capitalismo industrial; posteriormente se conceptúa el cuerpo como una suma de órganos en la sobremodernidad, y finalmente, el cuerpo se asume como acompañante posmoderno.

3. Es necesario evitar el enfoque individualista que supone la agencia como una construcción meramente personal, pues, si no cambia el contexto (por ejemplo, valorando más ese cuerpo reconstruido), el sujeto difícilmente cambiará su vida.
Ubicando este último sentido, en su seguimiento de la historia del cuerpo, David Le Breton plantea que la convergencia de prácticas relativamente recientes hace que el cuerpo sea vivido hoy, a menudo, como un accesorio de la presencia, un material a transformar para ponerlo a la altura de la voluntad del individuo. Lo anterior se deriva de concebir el cuerpo como "un objeto imperfecto, un borrador por corregir". En esta dirección, cabe la pregunta: ¿qué hace la cirugía estética? Se presume ${ }^{3}$ que se intenta cambiar el cuerpo para luego cambiar la vida. El físico-culturismo va en la misma línea: no es cuestión de contentarse con el cuerpo que uno tiene, sino hay que perfeccionarlo, controlarlo. Posteriormente 
señala que "a falta de poder controlar la existencia en un mundo que se presenta cada vez más inaccesible, se controla el cuerpo" (LE BRETON, 2011).

Frente a este optimismo social que el autor de Cuerpo y modernidad detecta, habría que señalar que en un gran sector de la población este "control" del cuerpo espejea con modelos propuestos desde los medios de comunicación, las industrias relacionadas a la moda (que no sólo norma el vestuario y sus aditamentos), las grandes empresas productoras de alimentos y los nuevos "expertos" que argumentan sobre las prácticas "necesarias" tendientes a la conservación de la salud y la estética del cuerpo y guían las decisiones cotidianas frente al modelo-espejo dominante (según la publicidad, aparentemente al alcance de todos) y frente al "qué dirán" anónimo que ya surge desde el propio interior, como sedimento de la relación social (ya facturada por los medios de comunicación masiva) y con el cuerpo propio 4 .

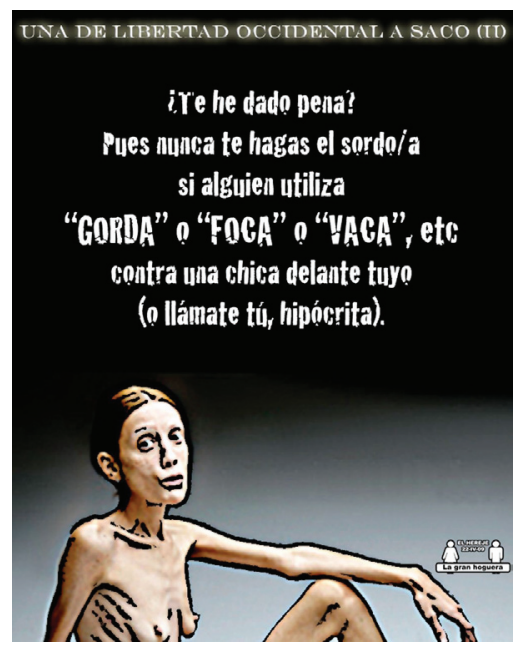

El cuerpo sujeto o confrontado al espejo (modelo imaginario dominante) que presiona.

En este sentido, hay que subrayar que las variaciones en la concepción estética del cuerpo han tenido consecuencias en la conservación o deterioro de la salud, así como en su significación. Los ideales o modelos de belleza que valoraban la robustez han devenido en su contrario y las prácticas y cuidados (excesivos) han contribuido al surgimiento de padecimientos que afectan a la salud, como la bulimia, la anorexia, la artrorexia ${ }^{5}$, entre otros.

El "re-des-cubrimiento" del cuerpo - que el puritanismo y el comunalismo había encubierto - se procesa desde hace ya aproximadamente cinco décadas, y se expresa en la libertad sexual y la reivindicación de su autonomía (el debate sobre la legislación del aborto y las marchas para exigir respeto de las prostitutas y de las comunidades LGTTBI, lo explicitaron con crudeza). Otros campos en

4. Algunos de estos fenómenos implosivos son la anorexia y la bulimia. Ricardo Navarro lo describe así: "La anorexiabulimia, como cuadro clínico, se distingue entre muchas otras características por actitud de extrema y obsesiva vigilancia sobre la ingesta alimentaria y la imagen del cuerpo, que se traduce en la renuencia a comer, aún a costa de la vida, o en el consumo excesivo y expulsión de los alimentos" (1999, p. 109).

5. Afán excesivo por informarse acerca de los "valores" y componentes de los alimentos a ingerir: grasa, calorías, proteínas, etc. 
6. Habría que introducir una reflexión sobre las interrelaciones entre las variaciones del ritmo corporal con el tiempo vivido y los imaginarios sobre el cuerpo como significante de la temporalidad. Los álbumes fotográficos familiares pueden ser el inicio de un diálogo inquietante en nuestros estudios sobre el cuerpo.

7. Quizá como una forma imaginaria de "detener" el tiempo aparecen las modasretro; en los últimos años, los "ochenta" reaparecen en sociabilidades que comprometen no sólo a quienes lo vivieron.

8. El énfasis de las cursivas son mías. los que se procesa este protagonismo del cuerpo (precisamente cuando lo virtual lo difumina en imágenes) es en la expansión intensificada de sus cuidados dietéticos (vinculados tanto a la salud, como a la estética), la obsesión por la juventud (que acelera la sensación del vértigo temporal), en las "prácticas sacrificiales" por conservar (aunque sea efímeramente) lo que el devenir del tiempo mina, inexorablemente ${ }^{6}$. Veamos ahora, en primer término, los sentidos tradicionales del cuerpo.

\section{El mito y el cuerpo en el orden cotidiano tradicional o comunitario}

En el orden simbólico tradicional, el cuerpo no podía ser investido con un ropaje narcisista: el espejo era el otro-comunitario, había que parecerse para ser, para pertenecer; así, el cuerpo también pertenecía a una red tupida de relaciones sociales de la comunidad. Su presentación se articulaba con un sistema simbólico que imbricaba el trabajo al mundo mágico-sagrado mediante los rituales y la fiesta, en una correlación significativa que concebía la relación cultura-naturaleza como un fluir recíproco. De esta forma, el cuerpo, aún investido con una carga simbólica muy fuerte y compleja, era considerado natural y, por ende, sólo se lo podía intervenir bajo condiciones de naturalidad inviolable que dicho imaginario (bajo la forma mito) proveía. Hoy, en las urbes, por la separación en campos y personajes (estatus, papeles o roles) - bajo cuyo ropaje habita la ciudad, y también como presencia que resalta el deseo, el trabajo que se separa de lo doméstico en las ciudades- el cuerpo se convierte en objeto de operaciones y técnicas "reconstructivas", y se desliga del orden simbólico para depender del olvido o de la proyección imaginaria "autónoma" (se puede "optar") que propicia la moda?.

En dicho orden tradicional, el cuerpo era sostenido y moldeado por el mito, los rituales y el control social, donde los primeros otorgaban legitimidad al último. El mito argumentaba la naturaleza del ser y en el rito lo ponía en escena y en la vida cotidiana se ejercía su ontología como hábito auto-vigilado. Alfredo López Austin señala la compleja practicidad del mito al destacar sus efectos en la vida cotidiana:

Y cuando el mito se narra, todos aquellos elementos sociales que obran sobre la narración y sobre los que la narración obra, alimentan memorias, provocan deducciones, se justifican, preparan futuras realizaciones del texto mítico y lo hacen vivir materialmente como lo que es, no una mera sucesión de sonidos o de palabras o de conceptos, sino un conjunto de interacciones sociales ${ }^{8}$. Porque cuando el mito no se narra, todos esos elementos siguen presentes; las relaciones del 
mito persisten. Por eso el mito no puede ser reducido a un texto. (LÓPEZ AUSTIN, 1996, p. 107).

El autor de Cuerpo humano e ideología agrega que la eficacia simbólica del mito no se limita a su explícita realización (narrativa o ritual), pues, entre otras cosas, “... rige los hábitos alimenticios y enriquece el caudal de creencias." (1996, p. 107). El mito, dice, dota de sentido a las "relaciones sociales disímbolas", las que adquieren sentido al vincularse en torno a dos núcleos: un acervo de creencias y una narración mítica y que las "relaciones sociales disímbolas no son solamente hechos sobre los que el mito ejerce su influencia directa. Forman parte del mito como su práctica, como su ejercicio, como la realización de sus creencias"; luego afirma que el mito "está en ellas, como elemento generador de sentido, como comunicador de congruencia" y que, "la creencia mítica está diseminada, presente en los actos rituales, en el poder, en la ingestión de alimentos, en el trabajo, en la cópula, en la integración de la familia" (idem, 1996, p. 109-110).

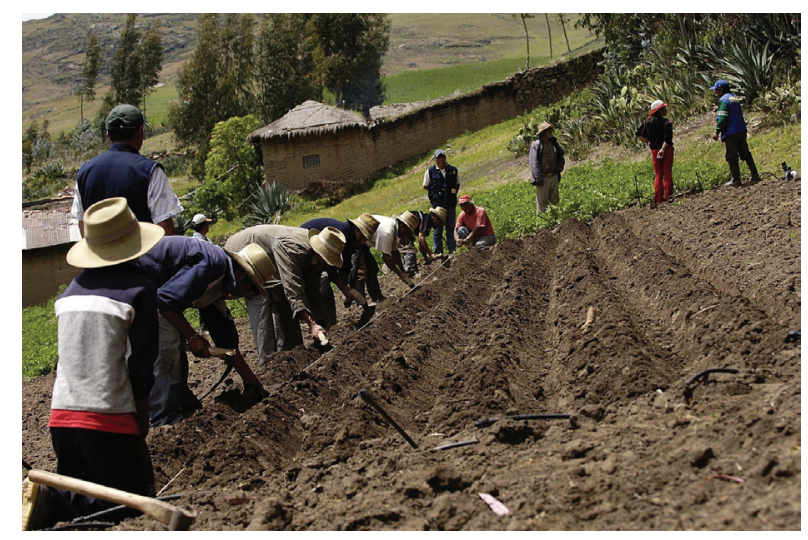

El trabajo agrícola condiciona la corporalidad semejante.

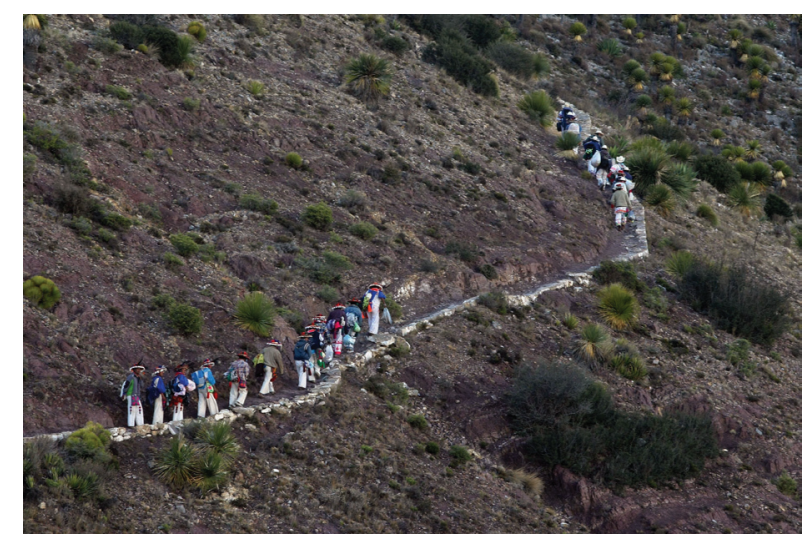

Los senderos hacia lo sagrado y la protesta en Wirikuta: la comunidad se expresa en la fachada personal. 
En estas condiciones, la constitución ontológica del cuerpo-persona se define refiriendo a los orígenes que el mito legitima, al mismo tiempo que modula el futuro como una continuidad social y temporal de la comunidad. Desde esta perspectiva, el pasado del mito no es el de la historia, pues ésta concibe transformaciones, mientras que el mito es fundante y se lo piensa inmutable. Así, el cuerpo se asocia a los significados y emociones que el mito prefigura, con cuyos modelos se lo cuida, expone, relaciona y usa:

En la parte superior de la cabeza (cuaitl) se ubican la conciencia y la razón; en el corazón (yollot/), todo tipo de procesos anímicos, y en el hígado (elli), los sentimientos y pasiones que pudieran estimarse más alejados de las funciones de conocimiento. Es una gradación que va de lo racional (arriba) a lo pasional (abajo), con un considerable énfasis en que era en el centro, en la confluencia donde radicaban las funciones más valiosas de la vida humana. Aún los pensamientos más elevados y las pasiones más relacionadas con la conservación de la vida humana se realizaban en el corazón, y no en el hígado ni en la cabeza" (LÓPEZ AUSTIN, 1996ạ: 219).

Esta noción-eje de centralidad que se traza en la geografía del cuerpo se proyecta, por ejemplo, en las comunidades indígenas andinas a las diferentes prácticas, espacios e instituciones como las demarcaciones territoriales (chawpi, urin, hanan: centro, abajo, arriba) y la elección de las autoridades (ni muy viejo -"quedado ya"-, ni muy joven -“loco todavía"-), etc.

Estas condiciones de producción cultural del cuerpo varían cuando dirigimos la mirada (en el tiempo y en el espacio) hacia la ciudad y su historia: vivir en la ciudad significa la predominancia de las relaciones contractuales, por lo que los referentes ontológicos de la vida y del cuerpo (identidad) se modifican.

\section{En la ciudad: el otro indiferente o el semejante difuso}

Es importante subrayar la función de la ciudad en la reconstrucción de nuestras relaciones con el cuerpo. Si "una ciudad puede definirse como un asentamiento relativamente grande, denso y permanente de individuos socialmente heterogéneos" (WIRTH, 1988 [1938], p. 167), y remarcamos el último carácter, tendremos una nueva mirada hacia la constitución de sus imágenes y las formas de construir el cuerpo. Wirth señala una de las características de la formación de las ciudades que afectan precisamente la constitución de la individualidad, que, como se puede colegir, es también la del cuerpo: 
Como la población de la ciudad no se reproduce a sí misma, debe reclutar a sus inmigrantes de otras ciudades, del campo (...) Así, históricamente la ciudad ha sido el crisol de razas, pueblos y culturas y un buen campo de cultivo de nuevos híbridos biológicos y culturales. No sólo ha tolerado, sino que ha favorecido las diferencias individuales, ha reunido personas de los confines de la tierra porque son diferentes $y$, así, son útiles unas a otras ${ }^{9}$, no porque fuesen homogéneas y de mentalidad similar. (ibid., p. 169).

El urbanismo como forma de organización social, según el mismo Wirth, derivó en la sustitución de los contactos primarios por los secundarios, (hoy se agregan dos tipos más de relaciones: terciarios y cuaternarios ${ }^{10}$ ); también contribuyó al debilitamiento de los nexos de parentesco, a la disminución del significado social de la familia, a la casi desaparición del vecindario, al socavamiento de las bases tradicionales de la solidaridad social, y a la función predominante de especialistas vinculados al cuidado y la conformación del cuerpo: salud, seguridad, educación.

En este sentido, hay una condición urbana adicional que interviene en la forma corporal. Si bien los contactos en la ciudad pueden ser, realmente, cara a cara, no obstante, son, dice Wirth, "superficiales, impersonales, transitorios y segmentados". De lo anterior deriva la "reserva, la indiferencia y el aspecto de suficiencia que los citadinos manifiestan en sus relaciones", los que pueden considerarse, agrega, "recursos para inmunizarse a sí mismos contra las expectativas y peticiones personales de los demás." (WIRTH, 1988 [1938], p. 171). Es éste el contexto en el que los urbícolas tienen que lidiar con sus cuerpos: ya no sujetos a un orden social de mutua dependencia e implicación sentimental y significativa con los otros, sino, inclusive, desplegando "relaciones de evitamiento", como lo advirtiera Erving Goffman (1989).

Estas características de la vida en las grandes ciudades, "abren" el cuerpo a la exploración y debilitan el control social, que en la comunidad era ejercida por casi todos, pues la "moral" que se adhería a la presentación del cuerpo se consideraba que "afectaba" al conjunto. Sin embargo, si bien la mayoría se sujetaba a las prescripciones colectivas, eran las mujeres el objeto privilegiado de vigilancia y sanción ${ }^{11}$.
9. El énfasis de las cursivas es mío.

10. Las relaciones terciarias se refieren a las que establecemos con otros que están al otro lado del medio (teléfono), a quienes no conocemos, y que dirigen a nosotros por la tecnología, orientándonos: "si quiere atención personalizada, marque 5"; las relaciones cuaternarias refieren al almacenamiento y manejo de nuestros datos personales, por diversas instituciones públicas o comerciales, sin que sepamos que ellas los poseen. Podría extenderse a la videovigilancia que ejercen las autoridades metropolitanas sobre los urbícolas en los diferentes contextos: calles, plazas, metro, en los entornos de las instituciones públicas y comerciales.

11. En este sentido Jane Darke, cita a Lord Shaftesbury, quien luchó para que las mujeres no fueran incorporadas al trabajo remunerado argumentando que: "Si ustedes corrompen a las mujeres, ustedes estarán contaminando las aguas de la vida desde su mismo manantial" (1998: 125), mostrando cómo, un sector de varones, se adjudican el papel guardianes de la "pureza" femenina. 


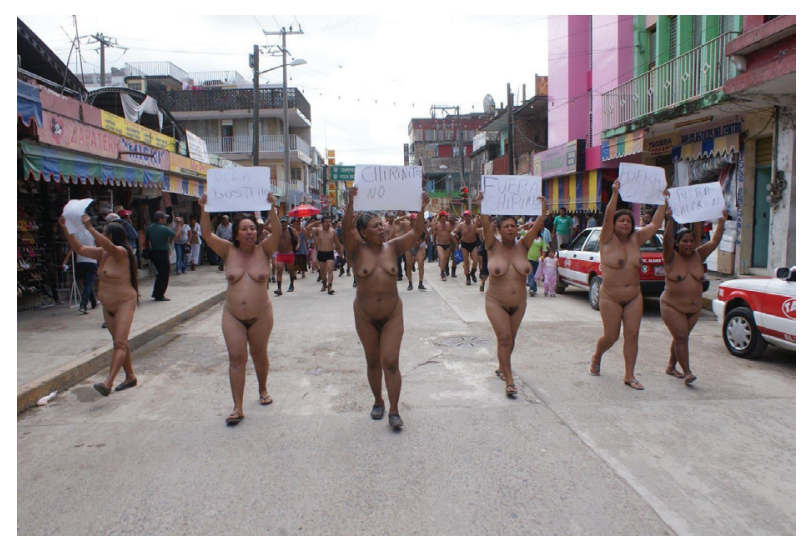

El cuerpo de las campesinas, sujetas a la vigilancia comunitaria, se libera en la protesta urbana.

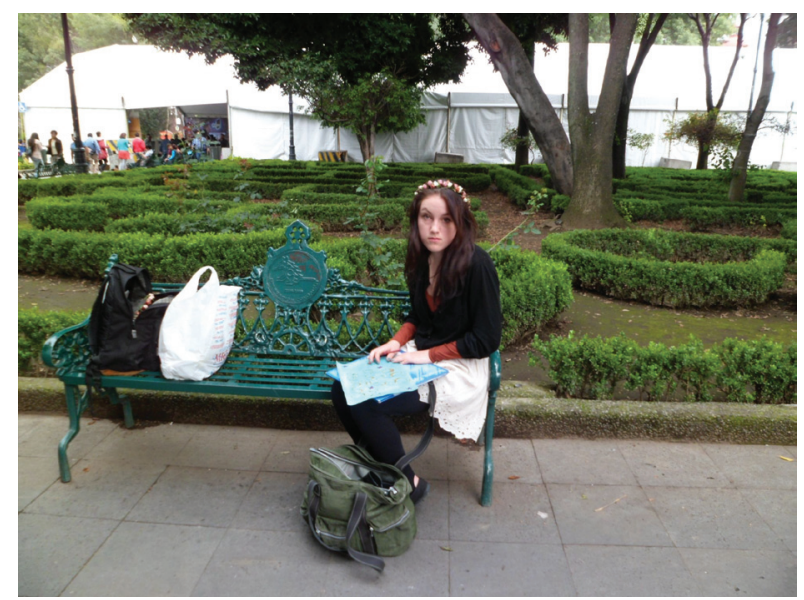

En la urbe, los jóvenes exploran nuevos estilos, bajo el manto protector de la indiferencia urbana.

En la ciudad se operan transformaciones importantes en la conceptuación y el uso del tiempo y del espacio. Es la ciudad la que posibilita realizar de manera más radical los cambios: un caso ilustrativo podría ser el caso de la juventud, que a partir de esa condición - inventada por la urbe - tiene tiempo, para invertirlo en su uso libre del trabajo, cosa difícil en el campo, donde la inserción en el proceso productivo es temprano. La oferta urbana para el entretenimiento es muy amplia y está sectorizada: por géneros, por edades, por clases, etc. Esta forma de la condición urbana contribuye a corroer más los lazos familiares y comunitarios, ofreciendo los ambientes para optar y explorar: los mapas mentales de los urbícolas es diferente, aún entre los miembros de una misma familia. No obstante, desde otro ángulo de enfoque, podemos observar que la ciudad puede ser caracterizada como "una evasión de las identidades impuestas desde una perspectiva patriarcal", también como "emocionante y liberadora" (DARKE, 1998, p. 116), con sus consecuentes efectos en los cuidados del cuerpo y su 
presentación.

También es importante destacar que si bien la indiferencia predomina en las relaciones personales de los urbícolas, es posible encontrar en las nuevos movimientos sociales y en las diferentes expresiones de protesta de la "sociedad civil", convergencias que aún siendo intermitentes, pueden ayudar a redefinir el sentido de la densidad urbana y las actitudes frente a la diversidad que la ciudad cobija, así como frente al poder autoritario.

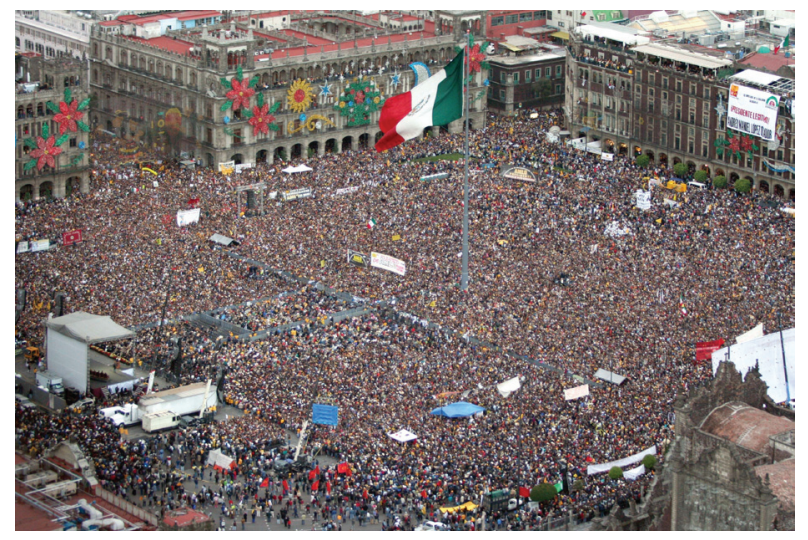

La densidad urbana no sólo es estar juntos en la protesta: el otro deviene en semejante.

\section{El cuerpo y el debilitamiento del Estado-nación}

La ciudad no ejerce presión sólo como recurso de "aplanamiento", "homogenización", anonimato e indiferencia. También influye al enervar su contrario, es decir, la sensibilidad frente al otro como materia prima - y efecto - de la fragmentación ya no sólo individual, sino de sectores y grupos.

En este sentido, George Yúdice señala que Brasil nunca fue un país homogéneo, y que, "pese a que el samba, el carnaval, la bossa nova y la música popular brasileña lo representaron como una nación con cierta coherencia". Asimismo, destaca que hoy, "ha surgido una nueva política de la representación que enfatiza la diferencia. Los medios masivos, los nuevos movimientos sociales y la cultura consumista asimétrica pero penetrante participan todos en esa política de representación que impide a cualquier grupo mantener el control de la imagen que suscita" (YúDICE, 2002, p. 162). Si bien esa "nueva política de representación" se expresa en prácticas culturales, éstas implican al cuerpo de manera protagónica: 
Mis raíces son pasos de danza/ cuando escucho funk nunca pierdo la esperanza/ dentro del salón jamás pienso dos veces/ bailo con emoción y durante varios meses/ bailo con rabia... ("Dance", éxito funk de Skova y Tadeu Eliezer, en YúDICE, 2002, p. 164).

\section{Yúdice remarca que}

12. El énfasis de las cursivas es mío.
13. Estas tres maneras de abordaje no se han aplicado solamente al estudio del cuerpo, pues ha sido una constante en las investigaciones referidas a la cultura popular y sus relaciones con la cultura hegemónica (Gramsci) o dominante, al conceptuarlas "pasivas" - reproductivistas (BOURDIEU Y PASSERON, 1997), contestatarias y transgresoras (desde el marxismo y el folclore) y confrontadas en desigual conflicto (BAJTIN, 1990; $\mathrm{Cl}-$ RESE, 1979, GARCÍA CANCLINI, 1988).
(...) aquí la emoción no se expande desde el individuo a una formación social más amplia ${ }^{12}$, sea esta un movimiento social o la nación; antes bien, expresa el deseo de poder actuar más libremente, de tener la libertad para hacerlo, lo cual se le niega permanentemente al favelado o suburbano apenas abandona el salón de baile. La emoción, experimentada como rabia en el acto de bailar, no se explota para un fin social y político de 'mayor envergadura'. Simplemente es la manera como los pobres construyen su mundo, pese a las restricciones del espacio y pese a la certidumbre (correcta) de que canalizar la rabia hacia alguna meta social o política solo puede convertirlos en ilusos" (2002, p. 165).

Por otro lado, en los estudios sobre el cuerpo, a nivel metodológico, se ha observado que su concepción ha puesto en cuestión dos maneras de enfocar sus problemáticas:

1. El cuerpo depende ahora de los medios de comunicación: ellos lo modelan; dichos medios reemplazan a la comunidad, a la iglesia y al Estado: proyectan una imagen de un cuerpo pasivo, receptivo, dócil.

2. El cuerpo es el último reducto de la resistencia, pues se puede moldear, tatuar, cambiar: proyectan un cuerpo activamente resistente.

Frente a las que se puede sostener una tercera opción,

3. Que enfatiza más bien la idea de que el cuerpo es un territorio del conflicto ${ }^{13}$.

Como una expresión de esta última opción, emplazando al cuerpo frente a uno de sus mayores modeladores que fue la Patria, el autor de La cultura como recurso, advierte que la identidad "no cala hondo" y lo ejemplifica en el sampleo, que Yúdice caracteriza como "opuesto a cualquier identidad nacional fija", observando cómo, muchos jóvenes ya no se arraigan en mensajes únicos, sino exploran y deniegan. Esta práctica, también puede expresarse en lo que hacen los televidentes con el control remoto cuando pasan de canal buscando, optando y a veces, o generalmente, no encontrando algo para ver. La pantalla lo 
enfrenta a uno a una diversidad de imágenes, corporales y de otro tipo y, aunque uno no sea consciente de los orígenes, los otros nos acompañan en nuestra intimidad, y sedimentan en nosotros. No necesariamente uno toma modelos desde esas imágenes, pero puede alimentar nuestras simpatías o aversiones, y también ayudarnos a relativizar aquello que consideramos "normal" o "natural" en los usos y significaciones del cuerpo propio, afianzando o reformulando la imagen de sí mismos.

\section{La noción de pureza en tiempos híbridos}

Según ciertos imaginarios populares de la globalización, ésta aplanaría al mundo y la sometería a una asfixiante uniformidad. Al contrario de estas predicciones y temores, su efecto en muchos territorios y comunidades ha sido la emergencia de una sensibilidad mayor hacia la diferencia oscilando las actitudes entre la curiosidad hacia el otro, el compromiso de los locales con el destino del planeta hasta la repulsión agresiva y violenta a lo que se considera intrusión. El proceso globalizador, con matices y niveles según sea su campo de expansión, también ha activado el recelo, la sospecha y el temor hacia el otro que se aproxima.

En este sentido, es interesante observar cómo Mary Douglas revisa y explica la inicial indiferencia hacia su libro Pureza y peligro (1966) dado que en el contexto construido por la guerra de Vietnam y los movimientos juveniles y sociales de 1968 rechazaban las diferentes formas de dominación, exclusión y violencia.

El comercio y la guerra se consideraban vergonzosos, junto con todas las formas de egoísmo e hipocresía; las religiones y rituales formalmente organizados fueron condenados, la formalidad como tal era rechazada en la vestimenta, el alimento, los comportamientos del cuerpo ${ }^{14}$. En aquel tiempo de éxtasis mientras los hippies exaltaban irresistiblemente el poder del amor, allí estaba yo, ofreciendo un libro que justificaba las cursivas es mío. mismas limitaciones que la sociedad le pone al amor. No era el momento apropiado para elogiar la estructura y el control. (DOUGLAS, 2007, p. 14-15).

La autora agrega que cuando ella escribía el libro, no pensó "que pronto el miedo a la contaminación estaría dominando nuestra escena política. Los apasionados principios morales de la década de 1960 cambiaron en la década de 1970 para enfrentar a monstruosos desarrollos tecnológicos que nos ponían en peligro. Comenzamos a temer la contaminación del aire, el agua, los océanos, el alimento" y, así, dice, "emergió una nueva disciplina académica - el análisis del riesgo - para el que Pureza y peligro comenzó a ser relevante de una manera 
15. La violación sexual, en algunos contextos socioculturales (religiosos, comunitarios), es uno de los actos de violencia que marcan la irreversibilidad. más generalizada de lo que jamás me había imaginado" (DOUGLAS, 2007, p. 17).

Hoy, las migraciones Sur-Norte, periferia-centro, que vinculan pobres con ricos, tanto en Norteamérica como en Europa, pero también en los propios países originarios, acercan a sectores que antes no se miraban y ni sentían tan cercanamente. Resurge, intensificada, la sensibilidad frente a la diferencia, y el cuerpo se manifiesta como un territorio de alta significación emocional.

Si observamos la noción de pureza en las diferentes materialidades en las que la significamos, veremos que la idea de un cuerpo puro es diferente de la que se tiene de la pureza un material, de un color o de un mineral. De manera convencional, un cuerpo puro es un cuerpo que no ha sido objeto de abuso (sexual) o no ha sido contaminado por los alimentos nocivos o prohibidos. La pureza, en algunos casos, puede recuperarse, en otros $\mathrm{no}^{15}$ y sus posibilidades y limitaciones, dependen de un orden cultural y social que la historia factura.

En su acepción material, la pureza indica la ausencia de un cuerpo extraño o de elementos dañinos. Esta imagen provee las bases para imaginar, por ejemplo, una sociedad demográficamente "pura", compuesta por descendientes de una misma "raza". En este sentido, la noción "sangre pura" es una figuración que se inspira en la supuesta pureza de los metales preciosos. En algunos países, (Alemania nazi como paradigma, pero no sólo en ella), el mestizaje social y la hibridación cultural pueden aparecer repulsivos, mientras que desde otras perspectivas pueden ser considerados como factores de enriquecimiento positivo.

Hoy, por lo anterior, debemos preguntarnos ¿quiénes, dónde y cómo significan y sienten la aproximación de/a la otredad como: dificultosa, posible o imposible, deseable o indeseable, repulsiva, seductora, bajo qué condiciones y en relación con - o frente a - quiénes? Las respuestas a esta compleja pregunta no sólo son el material que alimenta filosofías o doctrinas políticas y sociales: ellas atraviesan la vida misma, y no sólo la de los que tienen algún poder y algo más que perder. El cuerpo del inmigrante, así como el cuerpo juvenil y del anciano son ahora espejos ("vaso de lo imaginario", BAUDRILLARD, 1990, p. 27) que no se pueden obviar en los estudios no sólo de los que salen de sus regiones o países, sino también, y más aún, de quienes se quedan o los reciben.

En este contexto, purificar, en su sentido social, significa eliminar la polución y las manchas acumuladas y regresar al estado original puro. Es una inversión de su sentido material, donde purificar significa más bien advenir a un estado artificial y nuevo, bajo medios violentos, como en la metalurgia eliminando la impureza, transformando por la tecnología, creada de modo artificial; mientras que el sentido social supone que la pureza inicial ha sido trastornada, por intrusos, y es deseable (imperativo) recuperarla. La historia ha mostrado que 
muchos intentos de purificación, "limpiezas étnicas", por ejemplo, han devenido en masacres y etnocidios.

Existe la percepción de que la pureza se puede perder por contagio. La idea del contagio supone un riesgo y puede invocar políticas de contención, aislamiento y/o eliminación de la fuente; el que puede contagiar, se plantea, debe ser sometido a reglas de exclusión. Las imágenes actuales de xenofobia trastocan esta relación, pues no es esta posibilidad de "contagio" la que opera en las prácticas de exclusión, sino la idea de que la estética del paisaje humano se "contamina" con la presencia de los otros. La "limpieza" de las calles de mendigos y "locos" en diferentes ciudades basa sus políticas en esta conversión. La "cara amable" (muros desmontables, incluido) de las ciudades ofrecida a visitantes "distinguidos" es también una muestra de esta "cosmética" de la "política del paisaje", que no porque es una simulación, elimina lo que subyace como racismo y clasismo.

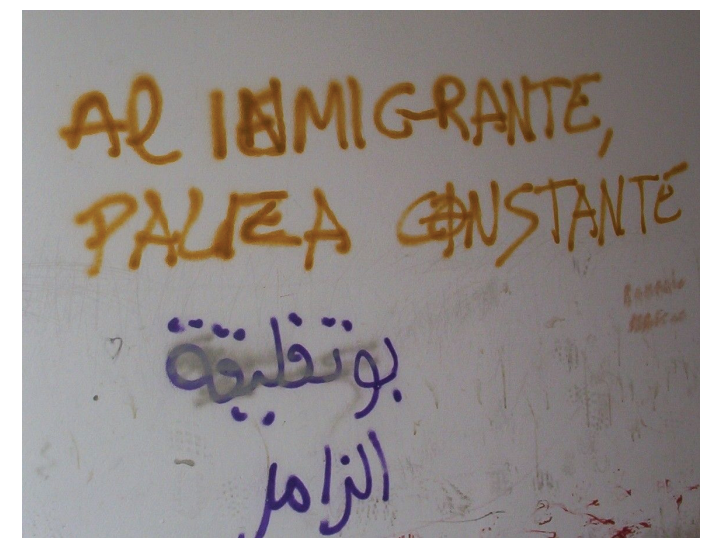

La intolerancia frente al cuerpo emigrante: "intrusión que contamina".

\section{Problemáticas contemporáneas referidas al cuerpo}

Debemos recordar que el cuerpo es ante todo una geografía (interior) y una piel-mapa (frontera y ligazón con el exterior) que en su interrelaciones sociales se reconstruye ${ }^{16}$. Las formas y mecanismos en que se lo moldea son: simbólicos, instrumentales y estéticos, y están condicionados por sistemas sociales, culturales y políticos, así como por la religión, la ciencia y el poder. Las transformaciones de las relaciones sociales repercuten en la forma en que cada quien observa la diferencia y la semejanza. A mayor individualismo no necesariamente le sigue una indiferencia hacia el otro.

La relación cuerpo-ciudad, entendiendo que ésta contiene la densidad y la diversidad modifica también la naturaleza significativa y emotiva del cuerpo. Así, si consideramos que la ciudad es propulsora de la heterogeneidad, y que ésta,
16. Sería interesante incorporar conscientemente las escalas de observación en los estudios del cuerpo. Por ejemplo, al determinarse como característica de la vida en las ciudades, la indiferencia, habría que ver cómo a nivel micro, en los contextos sociales en los que el urbícola frecuenta, encuentra el estímulo y el referente para cuidar su cuerpo: allí están los amigos, los compañeros de trabajo, los espacios sociales de consumo, etc. como factores de presión. 
17. Aquí, por ejemplo, sería interesante estudiar las formas en que los interlocutores buscan las informaciones que emiten mutuamente, es decir, las informaciones que damos "a pesar nuestro" en el lenguaje paraverbal o gestual; la sospecha que acude a indicios y señales para interpretar o comprender al otro, o simplemente para llegar, quizá, a lo que Clyde Mitchel (1999) caracterizaba como relaciones categoriales, como construcción urbana que al economizar esfuerzos para caracterizar a los urbícolas que se nos aproximan, apoya nuestra indiferencia, pero también proporcionan mapas para actuar al permitirnos definir la situación (GOFFMAN, 1989). entre otros factores presupone una compleja división social del trabajo, y que en la vida urbana el individuo muestra distintas facetas en diferentes dominios - del vecindario, del trabajo, del abastecimiento, del entretenimiento y del desplazamiento (HANNERZ) -, podemos observar cómo estas variaciones repercuten en la imagen del cuerpo y obligan al sujeto a administrar varias fachadas, una para cada actuación.

Por lo anterior, a nivel metodológico, puede plantearse la necesidad de asediar al dato desde varios ángulos, por ejemplo, perseguir al urbícola a través de su emplazamiento en los diferentes lugares y espacios de la ciudad, de sus historias de vida, cruzar con las jornadas y su ocupación con diferentes actividades, para, a través de sus relatos, estilo, modo de vida, observar sus transformaciones: ellas hablarán de cuánto espacio y/o territorio ocupa - como individuo o grupo -, cómo emplaza sus redes en la ciudad, cuál es la geografía de su experiencia vital y cómo separa sus papeles, qué información dona a los que integran su red ${ }^{17}$, y cómo se separan unos de otros por dichos emplazamientos, escondiendo sus otros papeles, o subrayándolos abusivamente para estafar o seducir, para ser otro en esa hiperbolización, etc. El urbícola, en cada una de sus presentaciones, es una fachada (literal y metafóricamente), administra su cuerpo y, puede, figurar como aquello que no es, o que es sólo en parte. Sería interesante observar los cruceros y biografías que, por ejemplo, se escenifican en los hogares y casas de atención de alcohólicos anónimos, neuróticos anónimos, comedores compulsivos y en las que atienden casos de violencia intrafamiliar, como espacios de nuevos disciplinamientos del cuerpo.

Como una proposición metodológica, es necesario observar las relaciones del cuerpo frente a varios ámbitos y situaciones que implican diferentes sujetos:

- Consigo mismo: las diferentes co-dependencias y autonomías, en contextos comunitarios o societales.

- Con el otro: deseado, temido, mediatizado. Diversidad que atrae o genera repulsión. El enemigo: el yo y la alteridad (el otro dentro). Confianza y desconfianza.

- El semejante construido por la étnia-raza, por la patria, por los medios, por la ideología, por la clase social. La violencia en contextos de debilitamiento del tejido social, de la semejanza y de la identidad.

- El indiferente: lo metropolitano que "aplana" al otro y que, no obstante, también enerva la auto-observación exigente.

Sin embargo de la compleja integralidad del cuerpo, no debemos olvidar que éste es observado especialmente desde el exterior como un soporte significante de diversas condiciones sociales, culturales, estéticas y morales. En la actualidad, podemos ver cómo esa condición sígnica y simbólica del cuerpo se 
utiliza conscientemente como continente de mensajes, como lo muestran expresividad juvenil indignada y la estética de la muerte del narcotráfico.

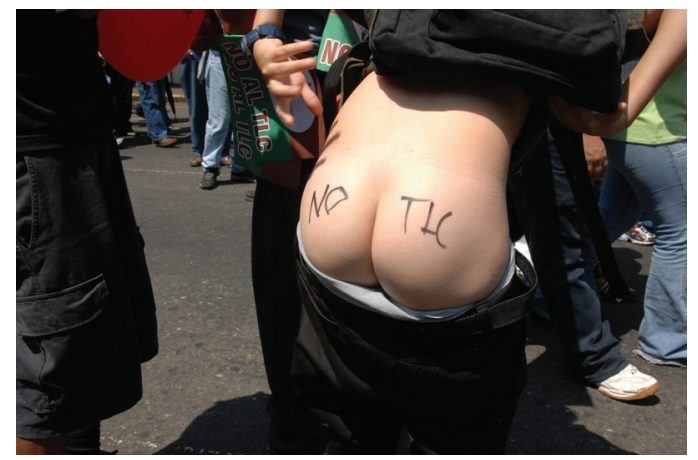

Las inscripciones en el cuerpo expresivo que simboliza: "no al Tratado de Libre Comercio".

Por otra parte, el cuerpo contemporáneo se reubica en el espacio (soledad urbana ${ }^{18}$ ) y el tiempo (en el afán de "detenerlo": maquillajes, cirugías). Esta situación redefine el imaginario del semejante que ya no espejea como otro-próximo sino como una incorporación que produce aversiones, indiferencia selectiva o seducción, según qué cuerpo se aproxima real o imaginariamente. En este sentido, la anorexia es la paradójica incorporación dramática del cuerpo-otro - ya no semejante, sino cuestionante - en la imagen del cuerpo-propio: esa imagen asedia al yo de manera agresiva.

\section{La Internet y el cuerpo}

La imagen de la "piel como interfase" entre el yo y el mundo se ponen en cuestión con las nuevas tecnologías porque posibilitan la contracción del espacio y tiempo. La inscripción -"pegar"- del cuerpo en las redes y la Internet producen una "presencia" que pueden acarrear riesgos. El acoso cibernético es uno de los problemas sociales que amenazan constantemente la integridad del cuerpo; llegando a situaciones extremas y fatales como el suicidio. El caso de Amanda Tod, quien antes de suicidarse narró la historia de cómo, al haber "puesto" en su página una foto de sus senos descubiertos, soportó el requerimiento amenazante de un acosador para que muestre otras partes de su cuerpo y con su autoeliminación desató una amplia reacción (en diferentes medios, pero especialmente en las redes y en Youtube ${ }^{19}$ ) es sólo una expresión de múltiples dramas que las tecnologías han posibilitado. Otra expresión serían los insultos y adjetivaciones que se muestra en los "foros" en internet. Habría que preguntarse ¿dónde queda el cuerpo (la imagen de sí mismo) del internauta cuando una imagen suya se expone en las redes? La imagen del cuerpo adquiere una "vida" propia y su cuidado sale del control de quien es su
18. Podemos extender esta condición (soledad) hacia el espacio público de la ciudad, donde se puede estar junto a muchos Otros, inclusive en una distancia íntima (HALL, 1991), sin por ello establecer una relación social: al contrario, se evitan unos a otros.

19. En menos de un mes, recibió cerca de dos millones de visitantes. 
"propietario".

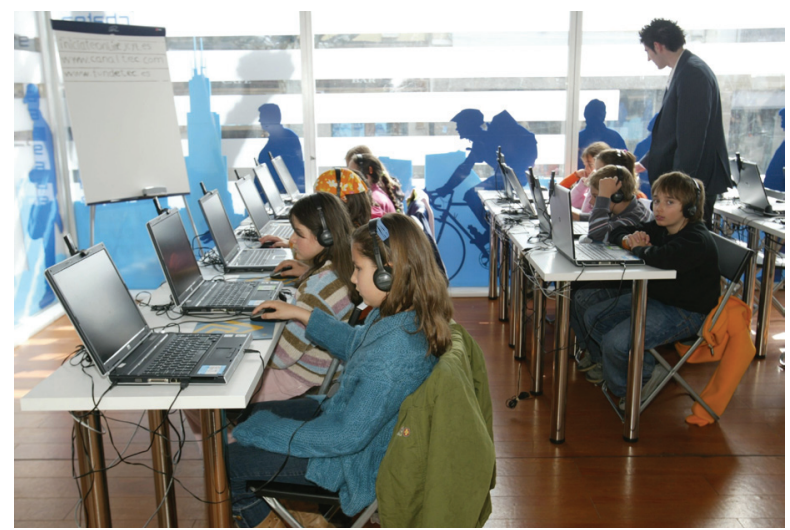

¿Dónde queda el cuerpo en el espacio virtual? Su imagen puede estar al otro lado.

20. Uso este término, acuñado por Erving Goffman, ya en sentido metafórico, y lo refiero a los controles que cada interactuante cibernético debe manejar, precisamente para controlar las impresiones de sí mismo, por ejemplo, retocando las imágenes personales. Puede que esta división esté en riesgo de perderse "conscientemente", cuando alguien decide el Chat con video. También por la vídeo-vigilancia que se cierne sobre la ciudad.
En el proceso interaccional, hay que observar las variaciones introducidas por la tecnología, pues hacerlo cara-a-cara y comunicarse por teléfono o chateando, implica de diferente manera al cuerpo y a la persona, aunque en todos los casos quien interactúa proyecta un personaje; y aquí propondría unas preguntas para investigar los cambios en la comunicación y socialización: ¿cuáles son las fronteras entre las "regiones" ${ }^{20}$ anterior y posterior, en el chat o la conversación telefónica, y cómo se las resguardan? ¿Qué tipo de sujeto crea la mediación electrónica y la distancia "próxima"? ¿Cuáles son sus consecuencias en el territorio y su comunidad?

\section{Cuerpo e identidad en las ciudades}

Otro elemento problemático es la relación cuerpo e identidad. Si bien hay que enfrentarlo en diversas escalas y no sólo por su emplazamiento situado, sino por el desplazamiento, la imagen de sí y del otro sufre transformaciones cuando la interlocución ya no es sólo con quienes se nos parecen. En ese contexto, es importante observar los recursos de negociación y performance, que por ejemplo despliegan los que migran, los sujetos étnicos, los transexuales. En esos viajes, sería interesante observar qué demarca y qué estereotipos se mantienen, enervan o difuminan. En algunos casos, fijarlo en categorías disminuye (evita) la angustia, en otros debilita la agresividad. Estos procesos modifican la relación entre cuerpo y memoria, que operaba como una síntesis del yo en el nosotros. La moda, en este contexto, opera como mecanismo del olvido. Asociado a estos cambios aparece la cuestión de la ambigüedad: que se puede expresar en la intersexualidad, el transgénero, emigración, la juventud. 
Así podemos ver los cambios en las relaciones del cuerpo y su entorno que redefinen las líneas de fuerza de la relación entre la libertad-autonomía y conexión-pertenencia, que implica variaciones en la identidad del yo. Las fronteras muestran nuevas aperturas, se modifican su rigidez y flexibilidad, así como los significados a los que se dirige. La ciudad opera como atenuador de las emociones que suscita, y la globalización oficia como la "caverna" de Platón que posibilita nuevos archivos para habitarlo.

Las situaciones metropolitanas, como el "cosmopolitismo", la hibridación-mestizaje, la soledad, la "libertad", la segregación la exploración, la indiferencia, el anonimato (éstos como mecanismos de atenuación), la tolerancia, la negociación, la intolerancia y la violencia, son contextos que producen cuerpos diferenciados, sin embargo, cada forma social y situación interpelan con desigual fuerza según dónde se ubique en las estructuras sociales y de poder. La clase y la étnia operan aún en el contexto que globaliza.

Otro componente fundamental de la vida contemporánea refiere a la vulnerabilidad asociada a la incertidumbre, productora del miedo. La vulnerabilidad no incide sólo en el cuerpo físico que refiere a su estética y a la salud, sino implica la desconfianza en el sistema (social y científico).

En este sentido, podría plantearse una problemática más abarcadora: ¿Cuáles son los efectos del fin de los grandes relatos (que tenían implicaciones ontológicas) en la vida cotidiana y la concepción del tiempo como memoria y proyecto y su relación con lo que el cuerpo hace hoy/aquí? ¿Cuáles sus implicaciones en las técnicas para vivir que le eran implícitos por proyectivos y orientados al futuro, cuánto influye la racionalidad cuando la trascendencia del acto no tiene ni norte ni puerto? ¿Es posible hablar ahora sí de una anomia más generalizada que subyace bajo un manto, que decorando la piel, oculta sus dramas? Y el cuerpo está en el centro de dichas transformaciones. Lo muestra la recuperación expresiva del cuerpo en las manifestaciones juveniles.

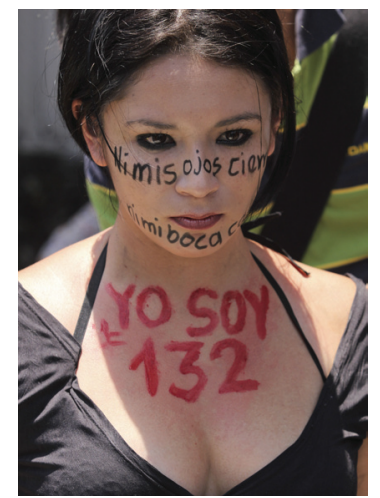

El cuerpo como soporte significante: su simbolismo se dirige a confrontar al poder autoritario. 
El cuerpo humano ha sufrido sucesivas transformaciones a lo largo de la historia; su naturaleza ha variado no sólo por los avances de la biología, la medicina y la protección pública sino también en su imaginario. El cuerpo sólo puede ser entendido a partir de conocer esas variaciones y cómo hoy a pesar de su aparente trivialización sigue conmoviendo las profundidades del ser cuyo pivote es el tiempo: el envejecimiento y la muerte. Ésta puede trivializarse o ritualizarse, aquel no.

\section{Cuerpo y miedo en la actualidad}

Si, como lo había señalado David le Breton, el cuerpo había devenido en acompañante, acentuando su insignificancia, desde otras condiciones de enunciado, existen otros actores sociales que radicalizan ese imaginario y lo reducen a una insignificante cosidad. En esta dirección, Michela Marzano, en su libro La muerte como espectáculo, señala su confrontación con una realidad nueva en la que las personas eran reducidas a cosas (agregaría que también en la pornografía) y se había llegado a la violencia en un "estado puro"; ella describe su contacto: "A lo largo de este estudio, visioné decenas de vídeos de degollaciones. Habría podido continuar, porque en Internet se encuentran muchos más. Pero había alcanzado el umbral físico y psíquico de la tolerancia" (2010: 12).

Utilizando su propia experiencia frente a las imágenes que proyectan dichos videos, constata una nueva producción, la de otra barbarie, a la que nomina la indiferencia, la que se caracterizaría, entre otras consecuencias, por buscar "anestesiar poco a poco, 'neutralizar', el juicio del espectador" (idem, 14). Ella agrega que dichas "imágenes extremas", se construyen "con un trasfondo de odio, odio tanto hacia uno mismo como hacia los demás", y estos vídeos "hacen un espectáculo de actos de barbarie" (MARZANO, 2010, p. 14). Frente a los propósitos señalados y los sentimientos que los motivan, habría que situar un triángulo comunicativo que redefine el análisis: está un sector de los musulmanes que producen estos videos motivados por el odio, también están quienes son emplazados en el campo enemigo que ubican como "occidente", y, completando el tercer ángulo, nosotros, los que vemos el video. Si el odio es la motivación, buscar la indiferencia es un despropósito. Sin embargo, la autora introduce una clave de lectura que es muy importante en la antropología, es decir la relación entre la violencia, el cuerpo y el ritual:

Como explica el filósofo Abdelwahab Medeb en ContrePrêches (2006), si el rito de sacrificio celebra la sustitución del hombre por el animal, la locura terrorista es su inversión simétrica. Nos hace descender a la barbarie pura, pues 
algunos islamistas llegan incluso a discutir en Internet sobre el detalle de las técnicas de degollación hasta ahora reservadas a las bestias para la fiesta del Aid. Existe en ello una desnaturalización de los ritos de sacrificio analizados por René Girard en La violencia de lo sagrado (1972). El rito de sacrificio se basa en dos tipos de sustituciones: en primer lugar, una víctima única sustituye a todos los miembros de la comunidad; en segundo lugar, la víctima del sacrificio (en general un animal) sustituye a la víctima propiciatoria. Por eso, este rito hace posible una especie de catarsis, es decir, una purificación, que previene del contagio de la violencia; la víctima es única y se trata, generalmente, de un animal. En cambio, los sacrificios humanos perpetrados por los islamistas no hacen más que encadenar una escalada sin fin de la violencia mediante la multiplicación sin fin de las víctimas ${ }^{21}$. Porque el espectáculo de la violencia a menudo tiene algo contagioso, una deriva a la que es muy difícil escapar. (MARZANO, 2010, p. 37-38)

Como un paréntesis, y para explicitar los nuevos temas del estudio del cuerpo, señalo que hay una gran semejanza con lo que viene ocurriendo en México con la violenta degradación del tratamiento del cadáver en la cultura narco ${ }^{22}$ :

Tengo el cuerpo acelerado/ el cerebro bloqueado/ y el cuerno bien pila. ("Pista 1", colección de narcocorridos)

Para seguir con la reflexión sobre la relación entre el cuerpo, la violencia y el miedo, antes, hay que ver cómo se elaboraba la esperanza en lo que sería una nueva sociedad; Zygmunt Bauman lo señala:

La modernidad tenía que ser el gran salto adelante: el que nos alejaría del miedo y nos aproximaría a un mundo libre de la ciega e impermeable fatalidad (esa gran incubadora de temores). Como bien reflexionaba Víctor Hugo, hablando con añoranza y elogiosamente sobre la ocasión: impulsada por la ciencia ('la tribuna política se transformará en científica'), una nueva era vendrá que supondrá el fin de las sorpresas, las calamidades, las catástrofes, pero también de las disputas, las falsas ilusiones, los parasitismos..., en otras palabras, una época sin ninguno de los ingredientes típicos de los miedos"; pero, agrega "los nuestros vuelven a ser tiempos de miedos". (BAUMAN 2007, p. 11)

El autor de Miedo líquido señala que todos los seres vivos conocen el miedo
21. El énfasis de las cursivas es mío.

22. En este sentido, la forma en que describen los narcocorridos las ejecuciones que realizan sus sicarios se expresa también en las imágenes observadas sobre cómo presentan los cuerpos asesinados: encajuelados, entambados, enhielados, decapitados, colgados, descuartizados, pozoleados, etc. El cuerpo mensaje, es también el cuerpo cosa: sólo un significante forjado en la barbarie. 
23. Según algunos reportes periodísticos, cerca de tres mil pequeños negocios cerraron. (responden con huida y agresión), pero el hombre conoce el miedo derivativo. "Podemos considerar ese miedo secundario como el sedimento de una experiencia pasada de confrontación directa con la amenaza: un sedimento que sobrevive a aquel encuentro y que se convierte en factor importante de conformación de la conducta humana aun cuando ya no exista amenaza directa alguna para la vida o la integridad de la persona" (BAUMAN, 2007, p. 11). Puede también ser descrito como "el sentimiento de ser susceptible al peligro", que se traduce en sensaciones de inseguridad y de vulnerabilidad. Concluye que el "miedo derivativo" adquiere una capacidad autopropulsora. Luego caracteriza tres tipos de miedo:

1- Amenazas al cuerpo y las propiedades.

2- Duración y la fiabilidad del orden social (del que depende la renta, el empleo o la supervivencia), es decir, la salud.

3- Amenazas al lugar de la persona en el mundo: identidad, posición, su inmunidad a la degradación y exclusión sociales.

En la actualidad, el Estado, incapaz de proteger de los dos primeros tipos de miedo, en medio de la globalización y del imperio del mercado se ve obligado a desplazar el énfasis de la "protección" desde los miedos para la seguridad social hacia los peligros para la seguridad personal. Sin embargo, afirma que hoy, todo es efímero, inclusive el miedo, pues muchos miedos entran acompañados de remedios, como los antivirus, las cremas para la piel, los seguros de vida, y así se efectúa la producción de consumidores asustados-esperanzados. El cuerpo tiembla.

Por otro lado, en el contexto de la globalización, existe la necesidad también de establecer las relaciones entre la acrecentada complejidad y la generación del peligro. Stephen Graham dice que "somos cada vez más dependientes de sistemas complejos y distanciados para el sustento de la vida" y, debido a ello, hasta "los pequeños trastornos y discapacidades pueden tener enormes efectos en cascada sobre la vida social, económica y medioambiental", sobre todo en las ciudades (en BAUMAN, 2007, p. 30). Esta situación fue vivida en Ciudad de México con graves consecuencias en la sensación de vulnerabilidad corporal y en la fragilidad economía ${ }^{23}$, durante la crisis de la influenza "porcina" de 2009.

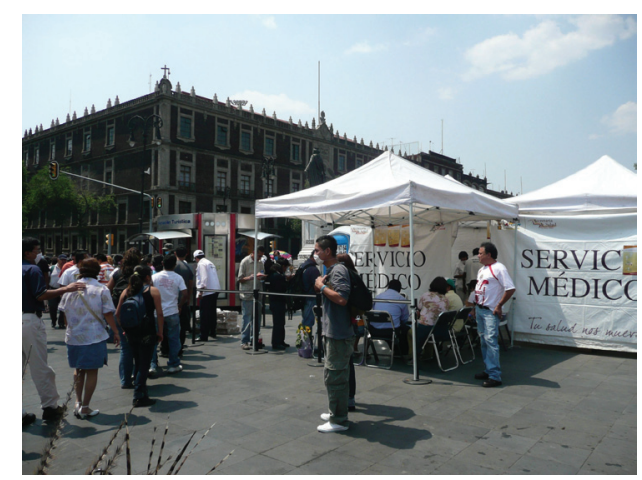

Nuevas formas de biopolítica: la influenza "porcina" sometió al control extremo bajo la presión del miedo. 
A la incomprensión de los orígenes del miedo, hoy se suma la individualización que impide respuestas conjuntas (si son posibles), pues la "dilapidación de los vínculos sociales" parece irreversible. En la crisis de la influenza, algunos testimonios lo expresaban dramáticamente: "tengo miedo, y estoy sola". Habría que recordar lo ya dicho, sin romanticismos que lo idealicen, que en las comunidades pre-urbanas, el cuerpo pertenece a un sistema social y simbólico que lo integraba, dificultando la soledad: en los pueblos es (casi) imposible estar solo (a).

Retomando la amplia complejidad ya señalada, podemos, con Arjum Appadurai, señalar que el temor puede ser un factor de violencia. También se puede constatar que en las actuales condiciones de la globalización y de las migraciones, la incertidumbre es un ingrediente de las interrelaciones y plantear la pregunta de cómo saber si "un individuo particular es realmente lo que él o ella dice ser, o lo que parece ser, o lo que ha sido históricamente" (APPADURAI, 2007, p. 19). El autor de El rechazo de las minorías. Ensayo sobre la geografía de la furia, agrega que esta incertidumbre se liga a lo que tienen derecho frente al Estado, en la distribución de bienes, introduciendo la competencia y agresividad aún entre quienes habitan la pobreza y la miseria.

De lo anterior se puede derivar que la violencia no es sólo el producto de identidades antagónicas, sino que ella misma es una de las formas que produce "identidades fijas y plenas, en parte para contrarrestar las incertidumbres acerca de la identidad que la circulación global inevitablemente produce" (APPADURAI, 2007 , p. 20), y que al volver imperativa la identidad exige movilizar el "compromiso pleno", llevando a consecuencias dramáticas, pues, por ejemplo, "el genocidio, después de todo, es un ejercicio que construye sentimiento de comunidad" (Philip Gourevitch, citado en APPADURAI, 2007, p. 21). En este contexto, se endurece la sensación de la mismidad y de la otredad, el cuerpo asume un simbolismo estructurante: matar al otro puede devenir en deber, no hacerlo es calificado traición.

Sí, como lo señala Appadurai, la minoría es el síntoma, y que el "problema subyacente es la diferencia misma", y que la eliminación de la diferencia "es la nueva marca distintiva de los actuales narcisismos predatorios a gran escala" (APPADURAI, 2007, p. 25-26), vemos que la figura del semejante-cuyo soporte significante es el cuerpo -, se diluye, desaparece. Históricamente, estas limpiezas se dan en contextos territoriales socialmente demarcados como exclusivos a escala nacional o regional, a contracorriente de la "homogenización" promovida por la globalización. Pero, por otro lado, esa eliminación es cada vez más difícil, ya que muchos límites se vuelven difusos, por ejemplo por la realización de matrimonios mixtos, lenguajes compartidos, etc. En este contexto, habría que preguntarse si ¿hay que inventar nuevas diferencias o extraerlos del pasado? Los jóvenes funkeiros de Río señalados por Yúdice proponen ese énfasis, 
24. Las cursivas son mías.

25. Las cursivas son mías. pero lo alejan del peligro de la exclusión y la violencia al no ligarse a movimientos sociales o políticos mayores. Los jóvenes brasileños señalados se diferencian de otras búsquedas, por ejemplo de las ligadas a fenómenos políticos asociados a cuestiones religiosas, como sería el caso de los países musulmanes: éstos enfatizan la diferencia desde el origen "sagrado" de las relaciones sociales, y éstas implican al cuerpo:

En esos casos, algunas ideologías generadas por diversas formas de desesperación ante la asimetría producen víctimas y mártires como instrumentos de liberación. Esos cuerpos singulares son un intento desesperado por reintroducir un elemento religioso a unos espacios de muerte y destrucción que han llegado a ser inimaginablemente abstractos. Podrían considerarse también respuestas morales, por horrorosas que sean, a los cuerpos torturados ${ }^{24}$, maniatados, humillados y fotografiados de los musulmanes bajo custodia americana en Irak y Afganistán. (APPADURAI, 2007, p. 28)

Este enfoque pone ante nosotros la posibilidad de verlos bajo la óptica del rito de sacrificio; sin embargo que, como se cuestionó Michela Marzano, su efecto es más violencia. Y, por otro lado, ya no es tan fácil distinguir las finalidades "ideológicas" de las vinculaciones emocionales de quienes ejecutan y de los que "visionan" las videograbaciones. Lo que aparecen, son cuerpos torturados y los significados que se adhieran desde uno y otro lado de la pantalla, pueden estar señalándonos precisamente la desaparición del concepto de prójimo y semejante. En este sentido, el narcotráfico en México, con su infernal escenografía del cuerpo torturado y exhibido como soporte significante de mensajes cruzados, es un reto para las ciencias sociales.

Para finalizar quisiera resaltar en el enfoque que se viene defendiendo en este artículo: la naturaleza del trabajo antropológico, y más aún cuando su objeto es el cuerpo, es análogo a la naturaleza del dispositivo simbólico: abre los canales para el entendimiento a partir de hacer converger los múltiples significaciones que se impregnan en hechos a los que el antropólogo enfoca y articula. En este sentido, quisiera recordar la naturaleza del símbolo, que es doble: "por una parte, al atravesar el espesor de las culturas, el símbolo se realiza en su esencia invariante $^{25}$. En este aspecto podemos observar su repetición. El símbolo actuará como algo que no guarda homogeneidad con el espacio textual que lo rodea, como un mensajero de otras épocas culturales (= otras culturas), como un recordatorio de los fundamentos antiguos (= eternos) de la cultura. Por otra parte, el símbolo se correlaciona activamente con el contexto cultural, se transforma bajo su influencia y, a su vez, lo transforma. Su esencia invariante se realiza en las variantes. Precisamente en esos cambios a que es sometido el sentido 
"eterno" del símbolo en un contexto cultural dado pone de manifiesto de la manera más clara su mutabilidad"26 que se reitera (agregaría); desplegándose también el conocimiento antropológico - como el símbolo -, a acumular y organizar lo que ocurre en nuestro alrededor como una nueva experiencia con el otro, es decir, con otros cuerpos, semejantes o diferentes.

En este sentido, se abren nuevas rutas de estudio, que si bien han sido objeto de reflexión, no se han asumido como objetos legítimos de la antropología, como la relación entre el deseo y el placer en un contexto de predominancia del mercado y el consumismo. Ambos, mercado y consumo, reformulan nuestra relación con nuestro cuerpo y, concomitantemente, redefinen la concepción de la relación social.

\section{Referências}

APPADURAI, Arjum. El rechazo de las minorías. Ensayo sobre la geografía de la furia, Tusquets Editores, Barcelona, 2007.

BAUDRILLARD, Jean. "Le plus bel objet de consommation: le corps", dans La société de consommation, Éditions Denoël, Francia, 1970, pp. 199-238.

BAUMAN, Sygmunt, Miedo líquido. La sociedad contemporánea y sus temores, Paidós, Barcelona, 2007.

BOURDIEU, Pierre y Jean-Claude Passeron, La reproducción, Laia, Barcelona, 1977.

CALDEIRA, Teresa Pires do Rio, Ciudad de muros, Barcelona, Gedisa, 2007.

CÁNEPA, Gisela, "Poéticas y políticas de identidad: el debate por la autenticidad y la creación de diferencias étnicas y locales", en Fuller (ed.), Interculturalidad y política. Desafíos y posibilidades, PUCP/UP/IEP, Lima, 2002 pp. 273-300.

CIRESE, Alberto, "Ensayos sobre las culturas subalternas." CISINAH, Cuadernos de la Casa Chata, México, 1979.

DARKE, Jane, "Un castillo para la mujer o un lugar donde ser ella misma", en C. Booth, J. Darke y S. Llenadle (coord.), La vida de las mujeres en las ciudades, Narcea Ediciones, Madrid, 1998, pp. 97-111.

"La ciudad modelada por el varón", en C. Booth, J. Darke y S. Yeandle (coord.), La vida de las mujeres en las ciudades, Narcea Ediciones, Madrid, 1998, pp. $115-130$.
26. Lotman, La semiósfera I, Cátedra, Madrid, 1996, p. 146. 
DOUGLAS, Mary, Pureza y peligro. Un análisis de los conceptos de contaminación y tabú 1966, Ediciones Nueva Visión, Claves, Buenos Aires, 2007.

. "La pureté du corps", Terrain, n³1, 1998, pp. 5-12.

. “Qu'est-ce qu'un événement?" Terrain, Número 38, 1998, http://

terrain.revues.org/document1921.html. Consultado el 5 octubre 2007.

GOFFMAN, Erving, La presentación de la persona en la vida cotidiana, Amorrotu, Buenos Aires, 1989.

HALL, Edward, La dimensión oculta, Siglo XXI, México, 1991.

LE BRETON, David, "El sentido del cuerpo", en HYPERLINK "http://www.tendencias21.net" www.tendencias21.net, Consultado en 2011.

LÓPEZ AUSTIN, Alfredo, Cuerpo humano e ideología. Las concepciones de los antiguos nahuas, UNAM, 1996a.

. Los mitos del tlacuache. Caminos de la mitología mesoamericana, México, Universidad Nacional Autónoma de México, IIA, 1996.

GIDDENS, Anthony. Modernidad e identidad del yo. El yo y la sociedad en la época contemporánea, Ediciones Península, Barcelona, 1998.

MARZANO, Michela, La muerte como espectáculo. La difusión de la violencia en Internet y sus implicaciones éticas, Tusquets, México, 2010.

VERGARA FIGUEROA, Abilio, “Alimentación, cultura y comunicación”, ponencia presentada al "Simposio anual: La nutriología en la clínica, la comunidad y la industria alimentaria: su papel en la promoción de la salud", Sociedad de Nutriología, México, 11, 12 y 13 de noviembre de 2004.

YÚDICE, George. El recurso de la cultura, Gedisa, Barcelona, 2002.

WIRTH, Louis. "El urbanismo como modo de vida", en Bassols y otros, Antología de sociología urbana, UNAM, México, 1988, pp. 162-182. 